\title{
Academic Performance, Employment, and Sleep Health: A Comparison between Working and Nonworking Students
}

\author{
Yu Chih Chiang ${ }^{1}$, Susan Arendt ${ }^{2} \&$ Stephen Sapp $^{3}$ \\ ${ }^{1}$ Department of Restaurant, Hotel, and Institutional Management, Fu Jen University, Taiwan \\ ${ }^{2}$ Department of Apparel, Events, and Hopiality Management, Iowa State University, USA \\ ${ }^{3}$ Department of Sociology, Iowa State University, USA \\ Correspondence: Yu Chih Chiang, Department of Restaurant, Hotel, and Institutional Management, Fu Jen University, \\ Taiwan
}

Received: February 25, 2020

Accepted: March 25, 2020

Online Published: March 26, 2020

doi:10.5430/ijhe.v9n3p202

URL: https://doi.org/10.5430/ijhe.v9n3p202

\begin{abstract}
Interest in overall health and well-being of students in higher education has grown. Retention and success in college has been linked to various health aspects including sleep and alchol usage. The purpose of this study is to: 1) assess sleep health and related behaviors, 2) examine relationships between sleep health and work conditions, and 3) determine if there is a relationship between sleep health and academic performance. Because many students work in service industries due to the flexibility of these jobs, comparisons are made between students working in service industries, students working in other industries, and non-working students. The online survey data from 736 participants, representing six U.S. universities, was analyzed. Findings indicated that average grade point was associated with sleep, work hours, and household income; student employees working in the service industry had a sleep score slightly lower than students working elsewhere.
\end{abstract}

Keywords: academic performance, college students, employment, shift work, sleep, sleep aids

\section{Introduction}

College students' academic ability, relevant work experiences, and health are all important for success. For students to successfully balance studying, working, and health wellness, sleep is one key aspect. Sleep is a basic physiological need for all humans and a vital component of health wellness; sleep also has potential linkage to academic learning. The impact of shift work, a common work type for college students, on sleep has received attention in recent years. Poor sleep has been associated with absenteeism, accidents, and various diseases (Caruso \& Rosa, 2012; Rosekind et al., 2010; U.S. Department of Labor [USDL, 2005]).

According to the Bureau of Labor Statistics, in 2004, millions of Americans were shift workers; of that group, the service industries had the highest proportion (38.3\%) of shift workers (USDL, 2005). More recently, Torpey (2015) summarized U.S. government data from 2011 to 2014 and showed that foodservice employees worked in the evening (between 6 p.m. and 10 p.m.) at a rate that was approximately twice as high as the average rate of total employed people. Additionally, service industries employ the largest number of young workers. According to 2019 data, there were 19,332,000 workers between 16 and 24 years old; of that group, 5,730,000 (29.6\%) young workers were employed in service industries, followed by 3,852,000 (19.9\%) in wholesale and retail trade industries (USDL, 2020).

Existing literature and government data suggest that students working in service industries, such as restaurants and hotels, may be at greater risk of sleep problems. However, few studies have explored sleep related behaviors and the effect of sleep on academic success for student employees. It is difficult for educators and employers to start conversations about students' studies, work, and sleep because there is a lack of associated studies. Therefore, the purpose of this study is to examine college students' sleep health, sleep behaviors, employment type, and academic performance. 


\section{Literature Review}

\subsection{Sleep and College Students}

In an extensive review, Hershner and Chervin (2014) indicated that daytime sleepiness, sleep loss, and irregular sleep schedules are common sleep problems for college students. The researchers summarized the causes and consequences of sleep problems including: class and/or work schedules, sleep disorders, and bad habits (e.g., using alcohol as a sleep aid, having caffeine after lunch, and using technology before bed). Consequently, these sleep problems may have a negative impact on a student's mood, driving ability, and academic performance (Hershner \& Chervin, 2014). There appears to be evidence, albiet self reported, that graduate students have better sleep behaviors than undergraduate students (Oswalt \& Wyatt, 2015). Partial explanation for this difference may be living environments. Undergraduates may be more likely to live on campus and experience sleep challenges related to campus residency such as noise and uncomfortable room temperatures (Qin \& Brown, 2017).

\subsection{Academic Performance}

Academic performance, often measured using grade point average (GPA), is a focal point of multiple studies. Researchers have assessed the impact of health behaviors, including sleeping and drinking, on academic performance (e.g., An, Loes, \& Trolian, 2017; Ruthig, Marrone, Hladkyj, \& Robinson-Epp, 2011). Although the impact of sleep problems on college students' academic performance has been studied for more than 40 years, findings are mixed. The key findings of previous works include: 1) college students who had very good sleep quality reported relatively high grades (Gomes, Tavares, \& de Azevedo, 2011), slept more than nine hours (Kelly, Kelly, \& Clanton, 2001), and did not delay their sleep (Lack, 1986); 2) daytime sleepiness, sleep duration, and sleep latency significantly impacted GPA (Chiang, Arendt, Zheng, \& Hanisch, 2014; Singleton \& Wolfson, 2009); and 3) correlations between sleep variables and GPAs were not consistent. Some researchers found that student GPAs were not significantly correlated with sleep variables, such as daytime sleepiness, dissatisfaction with sleep, sleep hours, and sleep quality (Howell, Jahrig, \& Powell, 2004; Peters, Joireman, \& Ridgway, 2005); whereas, others reported that GPA was negatively correlated with sleep variables such as daytime sleepiness, delayed bedtime, sleep duration, sleep schedule, time awake before getting out of bed, and differences between sleep timing on wordays and weekends (Haraszti, Ella, Gyöngyösi, Roenneberg, \& Káldi, 2014; Singleton \& Wolfson, 2009; Taylor, Vatthauer, Bramoweth, Ruggero, \& Roane, 2013).

In addition to sleep, other variables may impact college students' academic performance, such as parental expectation and socioeconomic status (Grossman, Kuhn-McKearin, \& Strein, 2011; Pearce, 2006; Vartanian, Karen, Buck, \& Cadge, 2007). When assessing $5^{\text {th }}$ grade students and following up with the same population at $8^{\text {th }}$ grade, Grossman et al. (2011) found that parental expectation, gender, and socioeconomic status were correlated with student achievement. In Vartanian et al's (2007) study, they found that Asian parents had high expectations for their children to complete college. Additionally, when comparing Whites with Chinese Americans, Pearce (2006) found that higher parental expectations were associated with higher student achievement for both groups. These findings suggest that socioeconomic status and parental factors may also have potential effects on college students' academic performance.

\subsection{Sleep and Employment}

It is common for college students to work while simultaneously attending school. A recent report targeting students between 16 and 24 years old, showed that about 5.6 (44.9\%) of 12 million college students were employed (USDL, 2019). College students intermingle work and study for different reasons. For those students who have financial needs, a job is necessary to cover tuition and/or living costs. For other students, industry experience (i.e., work experience or an internship) is required for graduation; for example, most hospitality programs require a certain number of intern or work hours to graduate (Kay \& DeVeau, 2003). However, it can be challenging for students to maintain the delicate balance of study, work, and sleep. Students may sacrifice sleep time to work and/or study; additionally, the pressures of work and their studies may impact sleep quality and quantity.

Researchers have studied the relationship between sleep, work, and student employees' grades, but these studies were limited because each sampled from only one institution. Sampling 185 student employees from a large private U.S. university, Trockel, Barnes, and Egget (2000) found that sleep habits and work hours might serve as predictors for student employees' grades. In another study sampling 903 student employees, Miller, Danner, and Staten (2008) explored the effects of work hours on sleep hours and student GPA; findings revealed that participants who worked 20 hours or more were less likely than those who worked less hours to achieve a GPA of 3.0 or greater.

Getting quality sleep can be beneficial for students' learning and memory abilities, and in turn, it may benefit their 
studies and work performance. Previous studies have reviewed evidence supporting the beneficial relationship between sleep, learning, and memory (Curcio, Ferrara, \& De Gennaro, 2006; Hershner \& Chervin, 2014). In addition, a study sampling 117 student employees from a large state university found a positive relationship between self-reported sleep quality and job performance (Chiang et al., 2014). However, other related literature has not found a strong connection between sleep and student employees' academic performance.

\subsection{Sleep and Working in Service Industries}

For students working in the service industry (e.g., restaurants and hotels), sleep and college studies may be negatively affected by irregular work schedules, long hours, night shifts, and weekend hours. At the same time, poor sleep may affect students' physical, mental, and social health, as well as their academic success. Brand, Hermann, Muheim, Beck, and Holsboer-Trachsler (2008) explored whether a nonstandard work schedule affected students' sleep and/or mental health by examining the relationships between sleep, work, and strain among students employed in service industries. The researchers showed that sleep quality was negatively correlated with depression and anxiety. They also found that increased work hours were associated with decreased sleep hours as well as higher levels of insomnia.

A few studies have focused on the relationship between sleep and academic performance for students working in service industries; one study found a weak relationship between sleep and academic performance (Chiang et al., 2014). It is possible that some students achieve high grades using strategies (e.g., drinking caffeinated beverages) to cope with sleep problems (e.g., daytime sleepiness, delayed bedtime, poor sleep quality, sleep disturbances, sleep deprivation). In other words, the effects of sleep on academic performance might be masked by other variables, which would pose a challenge to understanding the importance of sleep in higher education settings as well as to determine the importance of balancing study, work, and sleep for students.

\subsection{Research Questions}

The above literature review identified research gaps in current scholarship regarding the relationship between sleep, work, and academic performance in college students and student employees. Based on the review, the following research questions will be answered.

1) How do sleep health and related behaviors compare between students working in the service industry, students working in non-service industries, and students without jobs?

2) What is the relationship between sleep health and work conditions of college students, when comparing students working in service industries and students working elsewhere?

3) Are sleep health and related behaviors associated with academic performance when comparing students working in service industries, students working elsewhere, and students who are not working?

\section{Method}

\subsection{Population and sample}

The target population was undergraduate college students. The sample was recruited from six universities geographically dispersed throughout the U.S. offering a 4-year baccalaureate programs in service-oriented majors (e.g. foodservice and lodging). The database used for university selection was The Guide to College Programs in Hospitality, Tourism, \& Culinary Arts (ICHRIE, n.d.). Institutional Review Board approval was obtained prior to any human subjects contact.

\subsection{Instrument}

An online survey was developed and used for collecting data. An expert panel review and a pilot test were conducted to confirm the content validity of the instrument. Items were revised based on experts' and participants' comments. The three questionnaire sections are elaborated below: sleep health, academic performance and demographic items.

A measurement of sleep health was adapted from Buysse (2014, p. 17B) including five items: satisfaction with sleep, alertness during waking hours, timing of sleep, sleep efficiency, and sleep duration (SATED). Given SATED uses a 3 -point scale $(0=$ rarely/never, $1=$ sometimes, and $2=$ usually/always $)$, the range for the total score is $0-10$; whereby, established interpretation is that zero indicates poor sleep health and 10 indicates good sleep health. In addition, there were seven sleep-related items including amount of alcoholic beverage consumption, frequency of drinking alcoholic beverages, use of sleep aids, use of technology before bed (e.g., TV, video games, computers, laptops, tablets, and smartphones), and consumption of caffeinated beverages. Participants were also asked about their perceptions regarding the impact of technology and caffeinated beverages on sleep. 
Self-reported cumulative GPA was used as a measure of academic performance, which is similar to other studies (e.g., Kelly et al., 2001; Peters et al., 2005; Taylor et al., 2013). Demographic data were collectedincluding sex, age, race/ethnicity, classification status, work/internship requirement, parental education, parental expectation, and permanent address zip code. Zip codes were then linked to median household income for the county (U.S. Census Bureau, 2016). Parental expectation was measured by five items adapted from the family expectation-driven motivation subscale of the Student Motivation for Attending University (Cote \& Levine, 1997; Dennis, Phinney, \& Chuateco, 2005; Phinney, Dennis, \& Osorio, 2006). Parent expectation scale used a 5-point Likert-type scale (1 = strongly disagree to $5=$ strongly agree) and was found to be reliable with a Cronbach's alpha of .82. Items regarding employment were placed at the end of the instrument including workplace, managerial/supervisory responsibility, work shift, work hours, and length of employment in current job.

\subsection{Data Collection and Analysis}

A recruitment email with a link to the online survey, including an informed consent, was sent to students directly or via institutional contacts (e.g., research directors, department chairs, instructors) during the fall semester. Two reminders were sent to contacts at the beginning of the second and third week of the data collection period to increase the response rate as recommended by Dillman, Smyth, and Christian (2014). Demographic information and the scaled data were analyzed using descriptive statistics, Cronbach's alpha, correlations, and analysis of variance (ANOVA). The assumption of homogeneity of variance for between-group comparisons using t-tests or analysis of variance (ANOVA) was checked by applyling the Levene's test. Given the large number of college students working in service industries (e.g., restaurants, cafes, and hotels) and the industries' unique schedule requirements such as shift work, night hours, and irregular schedules, this study compared service employees, non-service employees, and students who did not have a job. Participants were divided into these three groups and the data were analyzed accordingly.

\section{Results}

\subsection{Sample Demographics}

There were 736 participants; of those, 175 (23.8\%) were students working in the service industry, 265 (36.0\%) were students working elsewhere, and 296 (40.2\%) were students who did not have jobs. Institutional contacts who sent out the survey link did not report numbers who received the link; therefore, a response rate could not be calculated. The majority of the sample was female $(\mathrm{n}=460,62.5 \%), 18-24$ years old $(\mathrm{n}=708,96.2 \%)$, Caucasian $(\mathrm{n}=501$, $68.1 \%)$, and juniors or seniors $(n=493,66.9 \%)$. Before graduating, about $30 \%(n=219)$ of participants were required to complete an internship and about $15 \%(n=110)$ of participants were required to have work experience. The majority of participants were from counties within the United States where the median household income was between $\$ 50,000$ and $\$ 74,999(n=513,76.5 \%)$. Approximately 40\% $(n=299)$ of participants reported that their parents' or guardians' highest education level was a bachelor's degree. Table 1 shows the details of the sample demographics.

In the sample, $440(59.8 \%)$ were employed; this percentage is higher than the reported percentage of employed U.S. college students $(44.9 \%$, USDL, 2019). Of the 440 student employees, $71.2 \%(\mathrm{n}=312)$ did not have managerial or supervisory responsibilities, $72.5 \%(\mathrm{n}=319)$ worked 20 hours or less per week, and $86.4 \%(\mathrm{n}=380)$ had worked at their current job for two years or less. Fifty-three percent $(n=235)$ of the student employees were shift workers. Of the 235 shift workers, $49.8 \%(n=117)$ were employed in service industries.

As shown in Table 1, the three groups (service, non-service, and not working) were similar in sex, age, race/ethnicity, classification status, median household income, and parental education. Higher percentages of requiring internship and work experience were found in the service group than the other two groups $(51.4 \%$ versus $23.0 \%$ and $23.1 \%$; $33.1 \%$ versus $6.8 \%$ and $11.5 \%$, respectively. Of the service group, 66.9\% (117 out of 175) were shift workers, and this percentage was almost twice as many $(38 \%)$ as reported by U.S. Department of Labor (2005). The service group had a higher percentage of participants working over 20 hours per week than the non-service group (38.9\% versus $20.0 \%$, respectively).

\subsection{Sleep and Related Behaviors}

The total sleep score indicated participants' satisfaction with sleep, alertness during waking hours, timing of sleep, sleep efficiency, and sleep duration (Buysse, 2014). On average, the total sleep score was $6.01( \pm 2.40)$ for the entire sample. The mean sleep scores for each group were: $5.83( \pm 2.36)$ for service, $6.00( \pm 2.43)$ for non-service, and 6.13 $( \pm 2.39)$ for non-working groups. Figure 1 shows a comparison of the sleep mean scores between the overall sample and sample groups. Based on these sleep scores, participants' sleep health was middle level, trending toward good 
sleep health (Buysse, 2014, p. 17B). Service student employees' sleep health was relatively worse than non-service student employees and students who did not have a job. However, using ANOVA, no significant difference in total sleep scores was found between groups (see Table 2).

Potential causes of poor sleep may include high frequencies of using alcohol as a sleep aid, using sleep aids, drinking caffeinated beverages in the afternoon to stay alert, and using technology before bed (Ebrahim, Shapiro, Williams, \& Fenwick, 2013; Rosenzweig, Breedlove, \& Watson, 2005). The majority of participants reported less than seven drinks per week ( $\mathrm{n}=578,78.6 \%$ ), which indicated that they were below the moderate level for drinking ("Drinking levels defined," n.d.). Most participants reported never consuming alcoholic beverages $(\mathrm{n}=625,85.1 \%)$ or using sleep aids $(n=574,78.2 \%)$ to help them fall asleep. However, it should be noted that the legal drinking age in all states where data were collected was 21 years of age. Of the total number of participants, $360(48.9 \%)$ were under the age of 21 and of those, 227 (30.8\% of the total sample) reported consuming at least one to two drinks per week. Additionally, the percentage of participants using alcohol as a sleep aid was $14.9 \%$, which was slightly higher than the percentage (11.4\%) reported by another undergraduate-focused study (Taylor \& Bramoweth, 2010). A large percentage of participants $(n=665,90.5 \%)$ usually used technology within an hour of going to bed; although, only $30.2 \%(\mathrm{n}=222)$ agreed that this behavior made it difficult for them to fall asleep. Similarly, the majority of participants sometimes consumed caffeinated beverages in the afternoon to help them stay alert $(\mathrm{n}=452,61.7 \%)$, and $35.1 \%(\mathrm{n}=258)$ agreed that this behavior made falling asleep difficult. Table 4 shows the means and standard deviations of sleep related behaviors and perceptions for the overall sample and sample groups.

Table 1. Sample demographics $(N=735-736)$.

\begin{tabular}{|c|c|c|c|c|c|c|c|c|}
\hline \multirow[t]{2}{*}{ Item } & \multicolumn{2}{|c|}{$\begin{array}{l}\text { Service } \\
(n=175)\end{array}$} & \multicolumn{2}{|c|}{$\begin{array}{l}\text { Non-Service } \\
(n=263-265)\end{array}$} & \multicolumn{2}{|c|}{$\begin{array}{l}\text { Not Working } \\
(n=295-296)\end{array}$} & \multicolumn{2}{|c|}{$\begin{array}{c}\text { Total } \\
(N=\mathbf{7 3 5 - 7 3 6 )}\end{array}$} \\
\hline & $n$ & $\%$ & $n$ & $\%$ & $n$ & $\%$ & $N$ & $\%$ \\
\hline \multicolumn{9}{|l|}{ Sex } \\
\hline Female & 124 & 70.9 & 174 & 65.7 & 162 & 54.7 & 460 & 62.5 \\
\hline \multicolumn{9}{|l|}{ Age } \\
\hline $18-24$ years old & 164 & 93.7 & 259 & 97.7 & 285 & 96.3 & 708 & 96.2 \\
\hline 25 years old and older & 11 & 6.3 & 6 & 2.3 & 11 & 3.7 & 28 & 3.8 \\
\hline \multicolumn{9}{|l|}{ Race/Ethnicity } \\
\hline African-American (non-Hispanic) & 7 & 4.0 & 8 & 3.0 & 6 & 2.0 & 21 & 2.9 \\
\hline Asian/Pacific Islanders & 24 & 13.7 & 31 & 11.7 & 66 & 22.3 & 121 & 16.4 \\
\hline Caucasian (non-Hispanic) & 121 & 69.1 & 187 & 70.6 & 193 & 65.2 & 501 & 68.1 \\
\hline Latino or Hispanic & 21 & 12.0 & 26 & 9.8 & 18 & 6.1 & 65 & 8.8 \\
\hline Others & 2 & 1.1 & 13 & 4.9 & 13 & 4.4 & 28 & 3.8 \\
\hline \multicolumn{9}{|l|}{ Classification Status } \\
\hline First-year & 23 & 13.1 & 18 & 6.8 & 69 & 23.3 & 110 & 14.9 \\
\hline Sophomore & 23 & 13.1 & 46 & 17.4 & 64 & 21.6 & 133 & 18.1 \\
\hline Junior & 47 & 26.9 & 105 & 39.6 & 72 & 24.3 & 224 & 30.4 \\
\hline Senior & 82 & 46.9 & 96 & 36.2 & 91 & 30.7 & 269 & 36.5 \\
\hline \multicolumn{9}{|l|}{ Internship Requirement } \\
\hline Yes & 90 & 51.4 & 61 & 23.0 & 68 & 23.1 & 219 & 29.8 \\
\hline No & 85 & 48.6 & 204 & 77.0 & 227 & 76.9 & 516 & 70.2 \\
\hline \multicolumn{9}{|l|}{ Work Experience Requirement } \\
\hline Yes & 58 & 33.1 & 18 & 6.8 & 34 & 11.5 & 110 & 14.9 \\
\hline No & 117 & 66.9 & 247 & 93.2 & 262 & 88.5 & 626 & 85.1 \\
\hline
\end{tabular}




\section{Median Household Income ${ }^{a}$}

$\begin{array}{lrrrrrrrr}\$ 25,000 \sim \$ 49,999 & 23 & 14.5 & 25 & 9.7 & 22 & 8.7 & 70 & 10.4 \\ \$ 50,000 \sim \$ 74,999 & 119 & 74.8 & 210 & 81.4 & 184 & 72.4 & 513 & 76.5 \\ \$ 75,000 \text { or more } & 17 & 10.7 & 23 & 8.9 & 48 & 18.9 & 88 & 13.1\end{array}$

\section{Parents' or Guardians' Highest Education Level}

Less than Bachelor's degree

$\begin{array}{llllllll}77 & 44.0 & 107 & 40.4 & 91 & 30.7 & 275 & 37.4\end{array}$

Bachelor's degree

$\begin{array}{llllllll}62 & 35.4 & 100 & 37.7 & 137 & 46.3 & 299 & 40.6\end{array}$

Professional degree

$\begin{array}{llllllll}36 & 20.6 & 58 & 21.9 & 68 & 23.0 & 162 & 22.0\end{array}$

Managerial/Supervisory Responsibility ${ }^{\mathrm{b}}$

$$
\text { Yes }
$$

No

\section{Work Shift ${ }^{\mathrm{b}}$}

Day shift

Evening, overnight, or rotating shifts

\section{Average Work Hours Per Week ${ }^{\text {b }}$}

Less than or equal to 20 hours

More than 20 hours

\section{Length of Employment ${ }^{\mathrm{b}}$}

2 years or less

More than 2 years

CGPA $>3.0$

$\begin{array}{rrrrrrrr}53 & 30.3 & 73 & 27.8 & - & - & 126 & 28.8 \\ 122 & 69.7 & 190 & 72.2 & - & - & 312 & 71.2\end{array}$

$\begin{array}{rrrrrrrr}58 & 33.1 & 146 & 55.3 & - & - & 204 & 46.5 \\ 117 & 66.9 & 118 & 44.7 & - & - & 235 & 53.5\end{array}$

$\begin{array}{lllllllll}107 & 61.1 & 212 & 80.0 & - & - & 319 & 72.5\end{array}$

$\begin{array}{lllllllll}68 & 38.9 & 53 & 20.0 & - & - & 121 & 27.5\end{array}$

Yes

$\begin{array}{llllllll}104 & 59.4 & 170 & 64.2 & 177 & 60.0 & 451 & 61.4\end{array}$ No

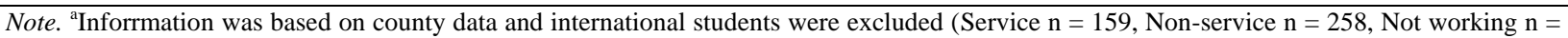
254, Total $\mathrm{n}=671) .{ }^{\mathrm{b}} \mathrm{N}=438-440$.

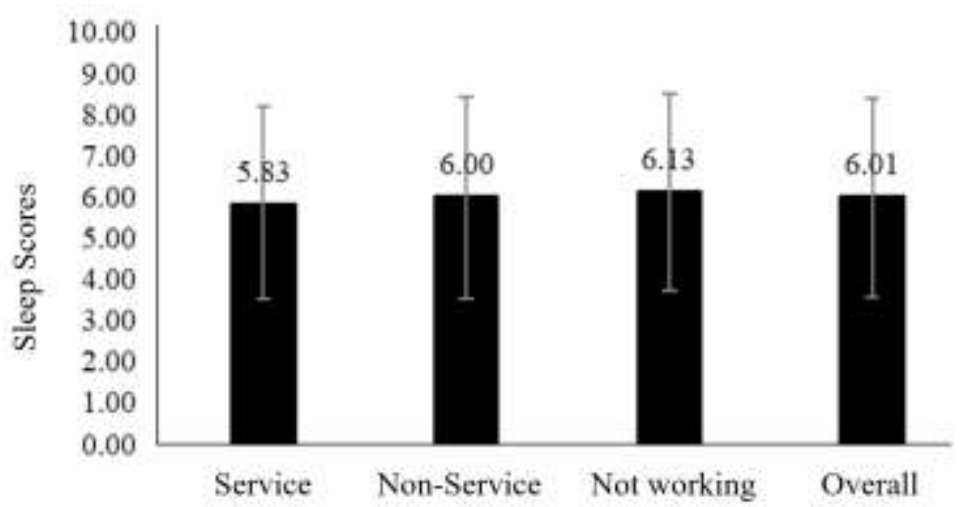

Figure 1. Means for total sleep scores by employment category

$(0=$ poor sleep and $10=$ good sleep $)$. Error bars represent one standard deviation. 
Table 2. Sleep score comparisons.

\begin{tabular}{|c|c|c|c|c|c|}
\hline Variable & $n$ & $M$ & $S D$ & $\boldsymbol{F}$ & $p$ \\
\hline Employment & & & & 0.844 & 0.430 \\
\hline Service industries & 175 & 5.83 & 2.36 & & \\
\hline Non-service industries & 265 & 6.00 & 2.43 & & \\
\hline Not working & 296 & 6.13 & 2.39 & & \\
\hline Use alcohol as a sleep aid & & & & 3.647 & 0.057 \\
\hline Yes & 109 & 5.61 & 2.16 & & \\
\hline No & 625 & 6.08 & 2.43 & & \\
\hline Take sleep aids & & & & 7.818 & $<.01$ \\
\hline Yes & 160 & 5.54 & 2.35 & & \\
\hline No & 574 & 6.13 & 2.40 & & \\
\hline Use technology before bed & & & & 0.245 & 0.621 \\
\hline Yes & 723 & 6.01 & 2.40 & & \\
\hline No & 12 & 5.67 & 2.46 & & \\
\hline Have caffeinated beverages & & & & 14.721 & $<.001$ \\
\hline Yes & 597 & 5.84 & 2.38 & & \\
\hline No & 135 & 6.71 & 2.35 & & \\
\hline Shift work ${ }^{a}$ & & & & 2.476 & 0.116 \\
\hline Yes & 235 & 5.77 & 2.35 & & \\
\hline No & 204 & 6.13 & 2.46 & & \\
\hline Work hours per week $^{a}$ & & & & 5.341 & $<.05$ \\
\hline Less than or equal to 20 & 319 & 6.09 & 2.32 & & \\
\hline More than 20 & 121 & 5.50 & 2.57 & & \\
\hline CGPA $>3.0$ & & & & 5.601 & $<.05$ \\
\hline Yes & 451 & 6.18 & 2.38 & & \\
\hline No & 284 & 5.75 & 2.41 & & \\
\hline
\end{tabular}

Table 3. Comparison of sleep related behaviors and perceptions.

\begin{tabular}{|c|c|c|c|c|c|c|c|c|}
\hline \multirow[t]{2}{*}{ Item } & \multicolumn{2}{|c|}{$\begin{array}{c}\text { Service } \\
\text { Workers } \\
(n=175)\end{array}$} & \multicolumn{2}{|c|}{$\begin{array}{c}\text { Non-Service } \\
\text { Workers } \\
(n=265)\end{array}$} & \multicolumn{2}{|c|}{$\begin{array}{c}\text { Not } \\
\text { Working } \\
(n=296)\end{array}$} & \multicolumn{2}{|c|}{$\begin{array}{c}\text { Total } \\
(n=736)\end{array}$} \\
\hline & $M$ & $S D$ & $M$ & $S D$ & $M$ & $S D$ & $M$ & $S D$ \\
\hline Amount of alcoholic drinks ${ }^{\mathrm{a}}$ & 1.45 & 1.476 & 1.42 & 1.222 & 1.45 & 1.439 & 1.44 & 1.373 \\
\hline Frequency of consuming alcoholic drinks $\mathrm{s}^{\mathrm{b}}$ & 1.17 & .481 & 1.22 & .595 & 1.23 & .572 & 1.21 & .560 \\
\hline Frequency of taking sleep aids ${ }^{\mathrm{b}}$ & 1.40 & .809 & 1.34 & .792 & 1.38 & .795 & 1.37 & .797 \\
\hline Perceived impact of technology on sleep ${ }^{c}$ & 3.20 & 1.061 & 3.08 & 1.171 & 3.11 & 1.065 & 3.12 & 1.103 \\
\hline Frequency of using technology before bed ${ }^{b}$ & 4.57 & .820 & 4.55 & .830 & 4.56 & .846 & 4.56 & .833 \\
\hline Perceived impact of caffeinated beverages on sleep ${ }^{c}$ & 3.14 & 1.197 & 3.05 & 1.152 & 2.95 & 1.205 & 3.03 & 1.185 \\
\hline Frequency of consuming caffeinated beverages ${ }^{\mathrm{b}}$ & 3.09 & 1.334 & 2.93 & 1.282 & 2.86 & 1.315 & 2.94 & 1.309 \\
\hline
\end{tabular}

Sleep score comparisons based on sleep related behaviors are shown in Table 3. The sleep score mean of participants who used alcohol as a sleep aid $(\mathrm{M}=5.61, \mathrm{SD}=2.16)$ was 0.47 points lower than those who did not $(\mathrm{M}=6.08, \mathrm{SD}=$ 2.43), although no significant difference was found. Research has suggested that drinking alcohol before going to sleep changes peoples' normal sleep cycles and makes them still feel tired after waking up; although, it does help 
them fall asleep quickly (Ebrahim et al., 2013). There was a significant difference between the sleep score of participants who used sleep aids $(\mathrm{M}=5.54, \mathrm{SD}=2.35)$ and those who did not $(\mathrm{M}=6.13, \mathrm{SD}=2.40)$. Increased frequency of nightmares has been identified as a common side effect of using sleep aids and thus have the potential to disrupt sleep (Rosenzweig et al., 2005).

There was no statistically significant difference between the sleep score of participants who used technology before bed $(\mathrm{M}=6.01, \mathrm{SD}=2.40)$ and that of those who did not $(\mathrm{M}=5.67, \mathrm{SD}=2.46)$. Almost all participates $(\mathrm{n}=723$, 98.2\%) used technological devices before bed although this result might be biased due to highly unequal group sizes. Researchers have linked this behavior to insufficient sleep, sleep latency, and daytime sleepiness (Exelmans \& Van den Bulck, 2016; Thomée, Eklöf, Gustafsson, Nilsson, \& Hagberg, 2007).

A significant difference in sleep mean scores was found among those who consumed caffeinated beverages. The score of participates who had caffeinated beverages in the afternoon or evening $(\mathrm{M}=5.84, \mathrm{SD}=2.38)$ was 0.87 points lower than those who did not $(\mathrm{M}=6.71, \mathrm{SD}=2.35)$. Negative effects of caffeine on sleep include: increased time to fall asleep, reduced sleep hours, and insomnia; although, effects vary by when, how much, and how often an individual consumes caffeinated beverages (McKim, 2007).

\subsection{Sleep and Work Conditions}

Work conditions assessed in this study included work type (shift worker or non-shift worker) and work hours (10 hours or less, 11-20 hours, and more than 20 hours). As shown in Table 2, the sleep score of shift workers ( $\mathrm{M}=5.77$, $\mathrm{SD}=2.35)$ was 0.36 points lower than that of non-shift workers $(\mathrm{M}=6.13, \mathrm{SD}=2.46)$, but no significant difference was found. There was a significant difference between the total sleep score of participants working 20 hours or less per week $(M=6.09, S D=2.32)$ and those working more than 20 hours $(M=5.50, S D=2.57)$. This finding is in line with Miller et al's (2008) study showing that college students working 20 hours or more were less likely to sleep seven hours or more.

\subsection{Sleep and Academic Performance}

The majority of participants reported their cumulative GPAs were higher than $3.0(n=451,61.4 \%)$. Similar percentages were found in the service $(n=104,59.4 \%)$, non-service $(n=170,64.2 \%)$, and non-working $(n=177$, $60.0 \%$ ) groups (see Table 1). A significant difference in total sleep scores was found between participants with CGPAs of 3.0 or less $(M=5.75, S D=2.41)$ than those with CGPAs higher than $3.0(M=6.18, S D=2.38)$ (see Table 2).

Potential indictors of cumulative GPAs included sleep, work hours, median household income, parents' or guardians' education level, and parental expectation. Correlations between cumulative GPAs and potential indicators were computed (see Table 4). Positive relationships were found between cumulative GPAs and total sleep scores $(\mathrm{r}=.115$, $\mathrm{p}<.01)$ as well as county median household income $(\mathrm{r}=.130, \mathrm{p}<.01)$. A negative relationship was found between cumulative GPAs and work hours $(\mathrm{r}=-.154, \mathrm{p}<.01)$. Parental influence on cumulative GPAs was not found. The present findings in combination with similar results of previous studies (Chiang et al., 2014; Chiang \& Arendt, 2016) may assist in explaining the weak relationship between sleep and student GPA. That is, despite a lack of sleep, students may use coping strategies to combat sleepiness or to assist them in falling asleep, which in turn helps them perform well academically.

Table 4. Correlations between cumulative GPA and potential indicators.

\begin{tabular}{lrrrc}
\hline Variable & $\boldsymbol{M}$ & $\boldsymbol{S D}$ & $\boldsymbol{r}$ & $\boldsymbol{p}$ \\
\hline Sleep score $^{\mathrm{a}}$ & 6.01 & 2.40 & 0.115 & $<.01$ \\
Work hours $^{\mathrm{b}}$ & 2.16 & 0.98 & -0.154 & $<.01$ \\
Median household income $^{\mathrm{c}}$ & $\$ 59,580.02$ & $\$ 12,442.95$ & 0.130 & $<.01$ \\
Parents' or guardians' education level $^{\mathrm{d}}$ & 5.13 & 1.93 & 0.002 & 0.961 \\
Parental expectation $^{\mathrm{e}}$ & 3.71 & 0.87 & -0.079 & $<.05$
\end{tabular}

Note. ${ }^{\mathrm{a}} 0=$ poor sleep health and $10=$ good sleep health.

${ }^{\mathrm{b}}$ Work hours included five categories ( $1=10$ hours or less, $2=11-20$ hours, $3=21-30$ hours, $4=31-40$ hours, and $5=$ over 40 hours).

${ }^{\mathrm{C}}$ Information was based on county data and international students were excluded.

${ }^{\mathrm{d}}$ Education level included eight categories $(1=$ less than high school, $2=$ high school diploma or equivalent, $3=$ some college, no degree, $4=$ postsecondary non-degree award, 5 = associate's degree, 6 = bachelor's degree, $7=$ master's degree, and $8=$ doctoral or professional degree).

${ }^{\mathrm{e}} \mathrm{A} 5$-point scale was used $(1=$ strongly disagree to $5=$ strongly agree $)$. 


\section{Discussion}

\subsection{Summary of Findings}

The findings and implications of this study are applicable to employed students, academic administrators and employers. On average, the sleep score reported by service student employees was slightly lower than non-service student employees and non-working students. The three sample groups reported similar sleep related behaviors. Participants who had low sleep scores reported long work hours. This might suggest that students who work more also have poor sleep health. The service student employee group had a higher percentage of shift workers, participants working over 20 hours, and internship/work experience requirements than non-service student employee group. Participants who had low sleep scores reported lower GPAs. It is difficult to determine if poor sleep leads to lower GPAs or if students who have lower GPAs might have poor sleep due to other variables not studied.Multiple indicators of student GPA were studied-including, but not limited to sleep-and significant relationships were found between sleep, work hours, household income, and student GPAs.

\subsection{Implications for Higher Education}

For academic administrators, there are several practical implications based on the findings of this study. Students struggling to balance sleep, study, and work, often sacrifice sleep to study more or work longer hours. However, this sacrifice may result in excessive sleepiness, depression, or anxiety and in turn, result in daytime dysfunctions (e.g., having difficulties understanding materials, taking longer to complete assignments/tasks) (Brand et al., 2008; Gillen-O’Neel, Huynh, \& Fuligni, 2013; Hershner \& Chervin, 2014). Living environment is another aspect that affects college student sleep quality and quantity; particularly those living in residence halls (Qin \& Brown, 2017). Looking at this issue from a broader perspective, the consequences of poor sleep health may impact college students' academic performance, job performance, financial well-being, and in turn, graduation and retention rates. This study is vital and applicable when developing curricula, improving work schedules, and emphasizing work-life balance programming.

\subsection{Limitations and Future Research}

This study had a few limitations. First, results of this study are not generalizable to other countries due to the limited sample size, differences in curriculum design, and percentage of college students holding jobs. Second, participants may underestimate their alcohol consumption due to impression management bias (i.e., ones' attempt to make a good impression on others) (Davis, Thake, \& Vilhena, 2010). Third, voluntary participation in the study may not respreent students with less sleep and more work demands because they may be less likely to participate in a survey. The accuracy of self-reported GPAs may be a concern; however, in research by Author (2013), self-report GPA data were $80 \%$ accurate (135 out of 172 participants) when comparing participants' self-reported cumulative GPAs to their official cumulative GPAs. Working students' sleep health and associated effects are understudied. Future researchcould assess mental health (e.g., stress, anxiety, and depression) as extraneous variables for a more comprehensive understanding of the association between sleep health, employment, and academic performance.

\section{Conclusion}

A better understanding of sleep will benefit academic administrators by increasing awareness of coping strategies (e.g., caffeinated beverages, sleep aids), informing program requirement decisions, and developing initiatives focusing on healthy lifestyles (e.g., text messaging to promote sleep health) (Jones et al., 2019). Additionally, findings of this study may increase employers' attention to sleep and influence work scheduling practices. If academic administrators understand the potential impact of sleep on overall student success and utlize study findings, greater emphasis may be placed on sleep as an overall wellness strategy. In turn, students may be encouraged to balance their time spent studying, working, and sleeping instead of sacrificing one in favor of another.

\section{References}

An, B. P., Loes, C. N., \& Trolian, T. L. (2017). The relation between binge drinking and academic performance: Considering the mediation effects of academic involvement. Journal of College Student Development, 58(4), 492-508. https://doi.org/10.1353/csd.2017.0039

Brand, S., Hermann, B., Muheim, F., Beck, J., \& Holsboer-Trachsler, E. (2008). Sleep patterns, work, and strain among young students in hospitality and tourism. Industrial Health, 46(3), 199-209. https://doi.org/10.2486/indhealth.46.199

Buysse, D. J. (2014). Sleep health: Can we define it? Does it matter? Sleep, 37(1), 9-17. https://doi.org/10.5665/sleep.3298 
Caruso, C., \& Rosa, R. R. (2012, March 08). Sleep and work. Centers for Disease Control and Intervention. Retrieved from http://blogs.cdc.gov/niosh-science-blog/2012/03/08/sleep-and-work/

Chiang, Y. C. (2013). The effects of sleep on performance of undergraduate students working in the hospitality industry as compared to those who are not working in the industry (Master's thesis). Available from ProQuest Dissertations and Theses database. (UMI No. 1540036)

Chiang, Y. C., \& Arendt, S. W. (2016). Most influential health issues on undergraduate students' academic performance for the past 10 years. In The 21st Annual Graduate Education and Graduate Student Research Conference in Hospitality and Tourism (p. 64). Retrieved from http://sthm.temple.edu/templegradconference/

Chiang, Y. C., Arendt, S. W., Zheng, T., \& Hanisch, K. A. (2014). The effects of sleep on academic performance and job performance. College Student Journal, 48(1), 72-87

Cote, J. E., \& Levine, C. (1997). Student motivations, learning environments, and human capital acquisition: Toward an integrated paradigm of student development. Journal of College Student Development, 38, 229-242.

Curcio, G., Ferrara, M., \& De Gennaro, L. (2006). Sleep loss, learning capacity and academic performance. Sleep Medicine Reviews, 10(5), 323-337. https://doi.org/10.1016/j.smrv.2005.11.001

Davis, C. G., Thake, J., \& Vilhena, N. (2010). Social desirability biases in self-reported alcohol consumption and harms. Addictive Behaviors, 35(4), 302-311. https://doi.org/10.1016/j.addbeh.2009.11.001

Dennis, J. M., Phinney, J. S., \& Chuateco, L. I. (2005). The role of motivation, parental support, and peer support in the academic success of ethnic minority first-generation college students. Journal of College Student Development, 46(3), 223-236. https://doi.org/10.1353/csd.2005.0023

Dillman, D. A., Smyth, J. D., \& Christian, L. M. (2014). Internet, phone, mail, and mixed-mode surveys: The tailored design method (4th ed.). Hoboken, NJ: John Wiley \& Sons, Inc.

Drinking levels defined. (n.d.). National Institute on Alocohol Abuse and Alcoholism. Retrieved from https://www.niaaa.nih.gov/alcohol-health/overview-alcohol-consumption/moderate-binge-drinking

Grossman, J. A., Kuhn-McKearin, M., \& Strein, W. (2011, August). Parental expectations and academic achievement: Mediators and school effects. Annual Convention of the American Psychological Association, Washington DC. https://doi.org/10.1037/e695232011-001

Ebrahim, I. O., Shapiro, C. M., Williams, A. J., \& Fenwick, P. B. (2013). Alcohol and sleep I: Effects on normal sleep. Alcoholism: Clinical and Experimental Research, 37(4), 539-549. https://doi.org/10.1111/acer.12006

Exelmans, L., \& Van den Bulck, J. (2016). Bedtime mobile phone use and sleep in adults. Social Science and Medicine, 148, 93-101. https://doi.org/10.1016/j.socscimed.2015.11.037

Gillen-O'Neel, C., Huynh, V. W., \& Fuligni, A. J. (2013). To study or to sleep? The academic costs of extra studying at the expense of sleep. Child Development, 84(1), 133-142. https://doi.org/10.1111/j.1467-8624.2012.01834.x

Gomes, A. A., Tavares, J., \& de Azevedo, M. H. P. (2011). Sleep and academic performance in undergraduates: A multi-measure, multi-predictor approach. Chronobiology International, 28(9), 786-801. https://doi.org/10.3109/07420528.2011.606518

Haraszti, R. Á., Ella, K., Gyöngyösi, N., Roenneberg, T., \& Káldi, K. (2014). Social jetlag negatively correlates with academic performance in undergraduates. Chronobiology International, 31(5), 603-612. https://doi.org/10.3109/07420528.2013.879164

Hershner, S. D., \& Chervin, R. D. (2014). Causes and consequences of sleepiness among college students. Nature and Science of Sleep, 6, 73-84. https://doi.org/10.2147/NSS.S62907

Howell, A. J., Jahrig, J. C., \& Powell, R. A. (2004). Sleep quality, sleep propensity and academic performance. Perceptual and Motor Skills, 99, 525-535. https://doi.org/10.2466/PMS.99.5.525-535

International Council on Hotel, Restaurant, and Institutional Education (ICHRIE) (n.d.). Guide to college programs in hospitality, tourism, \& culinary arts. Retrieved from http://www.guidetocollegeprograms.org/

Jones, K. E., Evans, R., Forbes, L., Schoenberger, Y. M., Heaton, K., \& Snyder, S. (2019). Research on freshman and sleeping habits: A text message-based sleep intervention. Journal of American College Health, 1-8. https://doi.org/10.1080/07448481.2019.1626860

Kay, C., \& DeVeau, L. T. (2003). A survey of lodging executives' views on internship programs and cooperatives. 
Journal of Hospitality \& Tourism Education, 15(2), 24-29. https://doi.org/10.1080/10963758.2003.10696765

Kelly, W. E., Kelly, K. E., \& Clanton, R. C. (2001). The relationship between sleep length and grade-point average among college students. College Student Journal, 35(1), 84-86.

Lack, L. C. (1986). Delayed sleep and sleep loss in university students. Journal of American College Health, 35(3), 105-110. https://doi.org/10.1080/07448481.1986.9938970

McKim, W. A. (2007). Caffeine and the methylxanthines. In L. Jewell (Ed.), Drugs and behavior: An introduction to behavioral pharmacology (6th ed., pp. 220-240). Upper Saddle River, NJ: Pearson Education, Inc.

Miller, K., Danner, F., \& Staten, R. (2008). Relationship of work hours with selected health behaviors and academic progress among a college student cohort. Journal of American College Health, 56(6), 675-679. https://doi.org/10.3200/JACH.56.6.675-679

Oswalt, S. B.,\& Wyatt, T. J. (2015). Who needs more sleep? Comparing undergraduate and graduate students' sleep habits in a national U.S. sample. International Journal of Higher Education, 4(1), 77-85. https://doi.org/10.5430/ijhe.v4n1p77

Pearce, R. R. (2006). Effects of cultural and social structural factors on the achievement of White and Chinese American students at school transition points. American Educational Research Journal, 43(1), 75-101. https://doi.org/10.3102/00028312043001075

Peters, B. R., Joireman, J., \& Ridgway, R. L. (2005). Individual differences in the consideration of future consequences scale correlate with sleep habits, sleep quality, and GPA in university students. Psychological Reports, 96, 817-824. https://doi.org/10.2466/pr0.96.3.817-824

Phinney, J. S., Dennis, J., \& Osorio, S. (2006). Reasons to attend college among ethnically diverse college students. Cultural Diversity and Ethnic Minority Psychology, 12(2), 347-366. https://doi.org/10.1037/1099-9809.12.2.347

Qin, P., \& Brown, C. A. (2017). Sleep practices of university students living in residence. International Journal of Higher Education, 6(5), 14-25. https://doi.org/10.5430/ijhe.v6n5p14

Rosekind, M. R., Gregory, K. B., Mallis, M. M., Brandt, S. L., Seal, B., \& Lerner, D. (2010). The cost of poor sleep: Workplace productivity loss and associated costs. Journal of Occupational and Environmental Medicine, 52(1), 91-98. https://doi.org/10.1097/JOM.0b013e3181c78c30

Rosenzweig, M. R., Breedlove, S. M., \& Watson, N. V. (2005). Biological rhythms, sleep, and dreaming. In Biological psychology: An introduction to behavioral and cognitive neuroscience (4th ed., pp. 424-455). Sunderland, MA: Sinauer Associates, Inc.

Ruthig, J. C., Marrone, S., Hladkyj, S., \& Robinson-Epp, N. (2011). Changes in college student health: Implications for academic performance. Journal of College Student Development, 52(3), 307-320. https://doi.org/10.1353/csd.2011.0038

Singleton, R. A., \& Wolfson, A. R. (2009). Alcohol consumption, sleep, and academic performance among college students. Journal of Studies on Alcohol and Drugs, 70(3), 355-363. https://doi.org/10.15288/jsad.2009.70.355

Taylor, D. J., \& Bramoweth, A. D. (2010). Patterns and consequences of inadequate sleep in college students: Substance use and motor vehicle accidents. Journal of Adolescent Health, 46(6), 610-612. https://doi.org/10.1016/j.jadohealth.2009.12.010

Taylor, D. J., Vatthauer, K. E., Bramoweth, A. D., \& Ruggero, C. (2013). The role of sleep in predicting college academic performance: Is it a unique predictor? Behavioral Sleep Medicine, 11, 159-172. https://doi.org/10.1080/15402002.2011.602776

Thomée, S., Eklöf, M., Gustafsson, E., Nilsson, R., \& Hagberg, M. (2007). Prevalence of perceived stress, symptoms of depression and sleep disturbances in relation to information and communication technology (ICT) use among young adults - an explorative prospective study. Computers in Human Behavior, 23(3), 1300-1321. https://doi.org/10.1016/j.chb.2004.12.007

Torpey, E. (2015). Careers for night owls and early birds. Retrieved from http://www.bls.gov/careeroutlook/2015/article/night-owls-and-early-birds.htm\#for-more-information

Trockel, M. T., Barnes, M. D., \& Egget, D. L. (2000). Health-related variables and academic performance among first-year college students: Implications for sleep and other behaviors. Journal of American College Health, 49(3), 125-131. https://doi.org/10.1080/07448480009596294 
U.S. Census Bureau, Small Area Income and Poverty Estimates (SAIPE) Program. (2016). 2015 Poverty and Median Household Income Estimates - Counties, States, and National [computer file]. Retrieved from https://www.census.gov/data/datasets/2015/demo/saipe/2015-state-and-county.html

U.S. Department of Labor, Bureau of Labor Statistics. (2005). Workers on Flexible and Shift Schedules in May 2004 (USDL 05-1198). Retrieved from http://www.bls.gov/news.release/pdf/flex.pdf

U.S. Department of Labor, Bureau of Labor Statistics. (2020). Current Population Survey (CPS). Retrieved from https://www.bls.gov/cps/cpsaat18b.pdf

U.S. Department of Labor, Bureau of Labor Statistics. (2019). College Enrollment and Work Activity of Recent High School and College Graduates - 2018 (USDL-19-0697). Retrieved from http://www.bls.gov/news.release/pdf/hsgec.pdf

Vartanian, T. P., Karen, D., Buck, P. W., \& Cadge, W. (2007). Early factors leading to college graduation for Asians and non-Asians in the United States. The Sociological Quarterly, 48(2), 165-197. https://doi.org/10.1111/j.1533-8525.2007.00075.x 